\title{
An Experimental Study of the Impact of Competition for Other People's Money: the Portfolio Manager Market
}

\author{
October 3, 2012
}

\begin{abstract}
In this paper we experimentally investigate the impact that competing for funds has on the risk-taking behavior of laboratory portfolio managers operating under the typical contractual arrangements offered to hedge fund managers. We find that such a competitive environment and contractual arrangement lead, both in theory and in the lab, to inefficient risk taking behavior on the part of portfolio managers. We then study various policy interventions, obtained by manipulating various aspects of the competitive environment and the contractual arrangement of fund managers, e.g., the transparency of the contracts offered, the risk sharing component in the contract linking portfolio managers to investors, etc. While all these interventions would induce portfolio managers, at equilibrium, to efficiently invest funds in safe assets, we find that, in the lab, transparency is most effective in incentivising managers to do so. Finally, we document a behavioral "Other People's Money" effect in the lab, where fund managers tend to invest the funds of their investors in a more risky manner than their own money, even when it is not in the investors' interest nor in the managers' incentives to do so.
\end{abstract}

\section{Introduction}

One issue of prominence these days is what many consider to be an excessive amount of risk taking in financial markets. What distinguishes these markets from others is the fact that in these markets portfolio managers must compete for the right to invest other peoples' money. In this paper we experimentally investigate the impact that competing for funds has on the risk-taking behavior of laboratory portfolio managers operating under the typical contractual arrangements offered to hedge fund managers. We construct a 
simple laboratory market for capital among portfolio managers where each manager offers a contract that shares a stylized version of various features that are commonly observed in real-world hedge fund markets. More precisely, the investor is not well-diversified across funds, the hedge fund manager's investment strategy is opaque, and the managerial contract is characterized by option-like compensation scheme according to which the manager receives (most of) the compensation only for returns in excess of pre-specified strike price (the details of this contract are described in Section 1.2).

In the simple model underlying our experiment, excessive risk taking is a feature of the equilibrium: the interaction between the competition for funds and the option-like contract for the manager leads to the inefficient outcome. Different policy interventions aimed at limiting risk taking on the part of managers do, in theory, rectify this result. We investigate several of these, which modify independently the competitive environment of fund managers and their contractual arrangements. More specifically, in one intervention (the Transparency treatment) we manipulate the competitive environment of fund managers by imposing transparency on their investment strategy; that is, by forcing the manager to announce (and commit to) the risk level of its intended investment before the investor invests. In a second intervention (the Risk Sharing treatment), we modify the managerial contractual incentive compensation scheme to require complete risk sharing between the manager and the investor. Finally, in a third intervention (the Restricted Competition treatment), we also change the managers' contractual arrangement by capping the strike price or promised return which managers can offer investors to limit how much competition could unravel.

In all these environments, at equilibrium, portfolio managers should efficiently invest funds in safe assets. Indeed, all of these interventions prove to substantially reduce risk taking in the experimental data. In particular, we find that the most efficient intervention in this respect is the Transparency treatment. However, these interventions fail to reduce risk taking completely or as thoroughly as predicted by the theory.

One possible explanation for the failure of our policy interventions to completely eradicate excessive risk taking relies on a behavioral phenomenon: in the frame of our experiment, managers are not investing their own money and this may lead them to a greater tendency to invest in risky projects. To investigate this hypothesis, we ran an "Own Money" treatment, which is identical to the Risk Sharing treatment except that in the Own Money treatment the manager is investing his own funds while in the Risk Sharing he is investing other people's money that he competed for. Interestingly, we find that managers tend to 
invest other people's money in riskier assets than they invest their own money. We interpret this difference as a manifestation of a framing effect, which we call the Other people's money effect. ${ }^{1}$ Indeed, while managers invested their own funds in the risky project only about $10.2 \%$ or $21.5 \%$ of the time (depending on the treatment), they invested other people's money in such projects $42 \%$ of the time in the Risk Sharing treatment. The Other peoples' money effect, therefore, represents a quantitatively significant behavioral inefficiency induced by competition for funds in our hedge fund laboratory. ${ }^{2}$ In other words, the excessive risk taking we observe in this paper may stem from two sources. The first is the natural result of competition in which excessive risk raking is a feature of the equilibrium. The second may be an Other people's money effect where subjects behave in an excessively risky way because they are not investing their own money.

Our paper, adds to the literature in a number of ways. To begin with, we are one of the very few papers that look at an evironment where different contractual arrangements interact with various aspects of competition in a financial market. In this respect the closest to our analysis is Asparouhova-Bossaerts-Copic-Cornell (2011) which also studies theoretically and experimentally competition in portfolio management. In this paper, however, the contractual environment is fixed and managers are paid a constant fraction of the funds they collect, independently of performance. On the other hand, others have investigated the impact of contracts on the behavior of agents in financial makets; see, e.g., Levitt and Syverson (2008), who look at contracts in real estate markets; and Ou and Yang (2003), Palomino and Prat (2003), He and Xiong (2010), and Chevalier and Ellison (1999), who investigate contracts for portfolio managers. None of these papers however integrate competition into their models, studying instead one person contracting environments.

A few related papers study experimentally the risk attitudes of subjects towards other people's money. Specifically, Brennan-Gonzales-Guth-Levati (2008) and ChakravartyHarrison-Haruvy-Rutstrom (2011) examine both risk attitudes of laboratory subjects towards their own uncertain payoffs as well as the uncertain payoffs of other subjects, finding a weaker dependence from the risk of the other subjects' payoffs than their own. ${ }^{3}$

\footnotetext{
${ }^{1}$ After the title of the 1991 Norman Jewison movie, with Danny De Vito.

${ }^{2}$ The Other people's money effect is consistent with the fact that hedge fund performance appears to be positively linked only to measures of the overall pay-performance sensitivity of managerial incentive pay (the overall "delta"), which include private ownership; see Agarwal-Daniel-Naik (2008). While private ownership requirements are included in incentive contracts to align the manager's and the investors' objectives, they might also have the effect of limiting the Other people's money effect.

${ }^{3}$ Eriksen and Kvaløy (2010), with a similar experimental design, find an opposite effect: agents handling other peoples' money behave in a more loss-averse manner and take less risks for their clients.
} 
The focus of the analysis of these papers is the social preferences of their subjects: the decision makers who make decisions for others are not incentivized to do so. We study instead the behavior of subjects who compete for funds and then invest them, fully incentivised to do so to maximize payoffs. In our paper, therefore, the Other peoples' money effect is a behavioral phenomenon, a specific form of framing, rather than a consequence of a specific form of social preferences.

The paper proceeds as follows. After a brief institutional introduction to hedge funds, in Section 2, we present a simple model of a market for capital and we prove some simple results about the equilibria of such markets. The capital markets in the model share some features of the capital markets in which hedge funds compete. The objective of the model, however, is to capture only some stylized features of these markets, and hence we abstract from several institutional details which might affect in a relevant manner the allocation of funds in these markets. We then introduce, in Section 3, our experimental design, mapping the model into a simple laboratory market. In Section 4 we present the results of our experiment. Finally, Section 5 concludes.

\section{The market for capital}

To put our analysis in its proper context, we first introduce briefly some relevant institutional aspects which characterize the market for capital and, in particular, hedge funds.

\subsection{Hedge funds}

Hedge funds are largely unregulated investment funds which, in the last twenty years have become increasing important in the capital markets. At its peak in the summer 2008, the hedge fund industry managed around $\$ 2.5$ trillion, according to Aima's Roadmap to Hedge Funds, Inechen-Silberstein (2008). ${ }^{4}$ Hedge funds typically compete for institutional and wealthy investors, requiring a substantial minimal investment tranche to participate in the fund (thereby imposing substantial diversification costs to investors). Moreover, hedge funds are characterized by their investment strategies and by the incentive schemes their managers are compensated with.

The investment strategies and styles of hedge funds are generally opaque, and are not revealed to investors. In other words, fund managers compete for investors in this market

\footnotetext{
${ }^{4}$ The first hedge fund was apparently founded by A.W. Jones, a sociologist and financial journalist, in 1949. In the 1990's, however, the industry was managing about $\$ 50$ billions; see Malkiel-Saha (2005).
} 
by signalling skills through past performance and through their incentive compensation scheme. Managers' compensation includes typically a small management fee (proportional to the investment tranche, of the order of $1-2 \%$ ) and a larger performance fee, of the order of $15-25 \%$ of returns exceeding the "high-water mark" (the maximum share value in a pre-specified past horizon). ${ }^{5}$ This incentive compensation scheme is equivalent to a call option with the "high-water mark" as strike price. Furthermore, the manager is subject only to limited liability, while it is relatively standard in the industry to require that a substantial fraction of the managers' private capital be heavily invested in their own fund. ${ }^{6}$

Option-like contracts, like those common in the hedge fund industry, are designed to signal managerial skills, ${ }^{7}$ but also induce managers to take high risks. ${ }^{8}$ A large empirical literature has documented that, in fact, $i$ ) hedge funds returns contain a significant excess risk-adjusted return due to managerial skills (or "alpha"), ${ }^{9}$ ii) hedge fund returns are significantly riskier than other investment forms (e.g., mutual funds). ${ }^{10}$ In particular, even though hedge fund returns display a low correlation with stock market indices, they are characterized by exceptionally large cross-sectional range and variation. ${ }^{11}$ Furthermore, the attrition rate of hedge funds in the market is very high (over $50 \%$ in 5 years from the $90 \mathrm{~s}) \cdot{ }^{12}$

\section{$2.2 \quad$ A simple model}

The type of markets we are interested in are the capital markets in which hedge funds compete for capital. In such markets typically,

\footnotetext{
${ }^{5} \mathrm{~A}$ norm in the market seems to be " $2 / 20$ " contracts: $2 \%$ management and $20 \%$ performance fee.

${ }^{6}$ See Fung-Hsieh (1999) and Goetzmann-Ingersoll-Ross (2001) for rich institutional details on the hedge fund industry.

${ }^{7}$ See, however, Foster-Young (2008) for a theoretical result suggesting lack of separation along the skill dimension in these contractual environments.

${ }^{8}$ More precisely, a rational portfolio manager facing a dynamic option-like contract will be lead to take extreme risk while the fund is below water (its return below the "high-water" mark), while he will invest more safely when just above water. See e.g., Carpenter (2000), Goetzmann-Ingersoll-Ross (2001), and Jackwerth-Hodder (2006) for the supporting portfolio choice theory; but see also Panageas-Westerfield (2007) for different results with infinite horizon.

${ }^{9}$ See Edwards-Caglayan (2001).

${ }^{10}$ See Brown-Goetzmann-Park (2001).

${ }^{11}$ See Brown-Goetzmann (2001) and, especially, Malkiel-Saha (2005).

${ }^{12}$ Even after accounting for survivor (and other related) bias, hedge funds paid (geometric) average returns $2 \%$ in excess of mutual funds in the period 1996 - 2003; see Malkiel-Saha (2005), Table $3-4$. See also Liang (2000) and Amin-Kat (2002).
} 
i) the size of the investment per investor is fixed, say $\$ 1$ (\$million, typically);

ii) the hedge fund manager receives a share, $\beta$, of all profits made above a "high-water mark" / strike price, $w ;{ }^{13}$ if the funds are lost, the hedge fund manager is not liable, that is, he/she only shares the upside risk in the contract and not any downside.

iii) the fund manager is under no requirement to offer the investor any specific information about her fund's investment strategy.

More precisely, when $\beta$, and $w$ are as described above and $R$ is the return earned by the fund in any given year, the cash flow accruing, respectively, to the investor ( $\left.\Pi^{\text {investor }}\right)$ and the hedge fund manager $\left(\Pi^{\text {manager }}\right)$ can be written as follows:

$$
\begin{aligned}
\Pi^{\text {manager }} & =\beta \max (0, R-w) \\
\Pi^{\text {investor }} & =\min (R, w)+(1-\beta) \max (0, R-w)
\end{aligned}
$$

\subsection{Contractual environments}

Consider a world with two hedge fund managers and one investor. The investor possesses a $\$ x$-chip to be invested, which the managers compete for. The manager who is successful in attracting the chip can invest it in one of two projects, called safe and risky.

The return on the safe project is a dichotomous random variable paying $R_{s}>0$ with probability $0<p_{s}<1$, and 0 otherwise. The return on the risky project is also a dichotomous random variable paying $R_{r}>R_{s}>0$ with probability $0<p_{r}<p_{s}<1$, and 0 otherwise. Note that the risky project, has a higher return when successful with respect to the safe asset; but the probability of success is higher for the safe asset. We assume however that the safe payoff has a higher expected return,

$$
p_{s} R_{s}>p_{r} R_{r}
$$

This assumption is called for, because we want to study the case in which investing in the risky asset is a dominated choice, absent the moral hazard implicit in the hedge fund manager's intermediation of funds.

We consider several alternative contractual environments (interventions) in which the hedge fund managers compete for the investor's funds. Each contract environment will

\footnotetext{
${ }^{13}$ We abstract from small fixed fees, which possibly have little effect on risk taking in practice in hedge fund markets.
} 
serve as a treatment in our experiment. To avoid considering a multi-dimensional competition problem, we consider the following extreme cases.

1. Baseline (hedge fund) contract. In this contract $\beta$ is fixed $=1$ and the managers compete for funds by choosing the water mark, $w$.

2. Risk Sharing contract. In this contract, in contrast to the hedge fund contract above, $w$ is fixed $=0$ and managers compete by offering different shares $\beta$ of the proceeds of their investments.

3. Transparency contract. This contract is identical to the hedge fund contract $(\beta=1$ and managers compete by setting $w$ ), except that when competing for funds, the manager is required to publicly commit to the project the funds will be invested in. Hence, an offer in this treatment is a pair ( $w$, safe) or ( $w$, risky). (This implicitly assumes the investment is verifiable).

Finally,we also study a contractual environment in which a legally binding condition restricts the hedge fund managers' offers,

4. Restricted contract. This contract is again identical to the hedge fund contract ( $\beta$ $=1$ and managers compete by setting $w$ ) except for the fact that we place an upper bound, $\bar{x}$, on the $w^{\prime} s$ that can be offered and hence require require $w \leq \bar{x}$

In any of the contractual environments described, after observing either $w$ or $\beta$, depending on the contractual environment, the investor decides which manager to invest his funds $(\$ x)$ with. The manager, before knowing if she will receive the funds decides which project, safe or risky, to invest them into. The manager who has received the funds will then go ahead and invest them as decided. After all investment decisions are made, the cash flow is realized and payoffs determined.

We specify these various contracts because we will be interested in how they affect the performance of the market for other people's money. As the propositions below indicate, these contracts can have a significant impact on the risk taking of managers and the subsequent welfare of our agents.

\subsection{Equilibria}

We now study equilibria in the different contractual environments. ${ }^{14}$ We concentrate first on the basic hedge fund contract, our baseline.

\footnotetext{
${ }^{14}$ See Matutes-Vives (2000) for a model of bank competition which resembles, along several dimensions, our laboratory hedge fund market.
} 
Result 1: In the Baseline contract, there exist a cutoff $w^{*}$ such that, if $w \geq w^{*}$ each manager has an incentive to invest the funds in the risky project (strictly so, if $w>w^{*}$ ).

In fact, $w^{*}$ is such that each manager is indifferent with respect to her investment, and it satisfies

$$
w^{*}=\frac{p_{s} R_{s}-p_{r} R_{r}}{p_{s}-p_{r}}>0
$$

Result 2: In the Baseline contract, if one manager offers $w_{1}$ and another manager offers $w_{2}$ such that $w_{1} \leq w^{*} \leq w_{2}$ and $\frac{w_{2}}{w_{1}}>\frac{p_{s}}{p_{r}}$, then the investor will give his chip to the manager who offered $w_{2}$. Likewise, in the Transparency contract, if one manager offers $\left(w_{1}\right.$, safe) while the other manager offers $\left(w_{2}\right.$, risky) and $\frac{w_{2}}{w_{1}}>\frac{p_{s}}{p_{r}}$, then the investor will give his chip to the manager who chose the risky project.

These results state that if one manager chooses the safe project, the other manager has an incentive to offer a high enough $w$ and choose the risky project. That is, there exists a risk premium $\left(\frac{p_{s}}{p_{r}}\right)$ such that a rational investor will be willing to leave the safe project for the risky one. In the transparency contract an investor is able to observe the contract in which his funds will be invested. Thus, an investor demands a compensation of at least $w_{2} \geq w_{1} \cdot \frac{p_{s}}{p_{r}}$ for high risk. In the baseline contract, if $w_{1} \leq w^{*} \leq w_{2}$ then the investor can infer that a manager that offered $w_{1}$ will invest in the safe project and a manager that offered $w_{2}$ will invest in the risky project (see result 1 ). Since $\frac{p_{s}}{p_{r}} w^{*}<R_{r}$ a deviation on the part of a manager to the risky project is always feasible. This is the case under a regularity condition bounding the relative return of the safe project, a condition satisfied by the parametrization of the game we take to the lab.

It is now straightforward to show, by a Bertrand competition argument, that

Proposition 1: In the Baseline contract, at equilibrium, both hedge fund managers offer $w=R_{r}$ and invest the funds in the risky project. ${ }^{15}$

Proposition 2: In the Transparency contract, at equilibrium, both hedge fund managers offer $w=R_{s}$ and invest the funds in the safe project.

Proposition 3: In a Restricted contract, with $\bar{x} \leq w^{*}$, at equilibrium both hedge fund managers offer $w=\bar{x}$ and invest the funds in the safe project.

\footnotetext{
${ }^{15}$ This result holds true more generally, when managers in hedge fund markets compete by choosing both the share, $\beta$, of all profits made above a "high-water mark"/strike price, $w$, and the "high-water mark"/strike price, $w$ itself; see Appendix 1.
} 
Proposition 4: In a Risk Sharing contract, at equilibrium both hedge fund managers offer $\beta=0$ and invest the funds in the safe project.

Note that these contracts lead to different results in the market. For example, under the Baseline contract, competition forces $w$ up to the level of $R_{r}$ and all funds are invested in the risky project. In all the other contracts, however, at the equilibrium the funds are invested in the safe project with different equilibrium w's in the Transparency and Restricted contracts and $\beta$ in the Risk Sharing contract. For example, in the Risk sharing contracts where managers compete by offering $1-\beta$ and where $w=0$, the only equilibrium is one involving both investors investing in the safe project and $\beta=0$. In this contract the incentives of the investors and managers are perfectly aligned so that the managers should invest the investor's chip as if he was investing his own money. In the Restricted contract funds should be invested in the safe project since we restrict $\bar{x} \leq w^{*}$.

\subsection{Parametrization}

In our experiments we investigate one particular parametrization of this model. In this parametrization the safe project has a cash flow of 7 tokens if successful, with probability $.9,\left(R_{s}=7, p_{s}=.9\right)$ while the risky project has a cash flow of 10 tokens if successful, with probability .5, $R_{r}=10, p_{r}=.5$. Without loss of generality, if we restrict $w$ to be in $[0,10]$ it is easy to show that, in this parametrization, $w^{*}=3.25$ and all our assumptions are satisfied, i.e., $6.3=p_{s} R_{s}>p_{r} R_{r}=5$ and $\frac{p_{s}}{p_{r}} w^{*}=5.85<R_{r}=10$. Given this parametrization we have the following equilibrium predictions for our different contracts.

Table 1: Equilibrium Predictions

\begin{tabular}{l|l|l|l}
\hline \hline Contract & Investment & $\beta$ & $\omega$ \\
\hline Baseline & Risky & NA & 10 \\
Risk Sharing & Safe & 0 & NA \\
Transparency & Safe & NA & 7 \\
Restricted Competition & Safe & NA & $\bar{x} \leq 3.25$ \\
\hline \hline
\end{tabular}




\section{Experimental design}

Our experimental design attempts to implement the market for funds outlined above. ${ }^{16}$ The experiments were run at the experimental lab of the Center for Experimental Social Science at New York University. Students were recruited from the general undergraduate population via E-mail solicitations. In total 170 students participated in the experiments, which lasted approximately 45 minutes and students earned on average $\$ 20$. Each different contractual environment represents a treatment in the experiment.

The Baseline treatment is the hedge fund contract environment, which we introduce first. When subjects arrived at the lab they were divided into groups of three with two managers and one investor in each group. The experiment consisted of 20 identical decision rounds. In each round the investor was endowed with one "investment chip". Each round started by each manager simultaneously selecting a promised $w \in[0,10]$. The managers also choose which project, safe or risky, they intend to invest in. The w's are announced to the investor in the market, but not the investment decision, which is kept private. After both managers choose their $w$ 's, the investor decides who to invest his chip with. The selected manager then has the right to make the investment that she decided on. The other manager can make no investment in this round. We ran our market with only one investor in order to maximize competition and with only two managers in an effort to minimize the number of subjects needed (and hence the amount of money required).

After the investment decisions were made the chosen project was played out and payoffs determined. A successful investment in the risky project paid $10-w$ tokens to the manager and $w$ to the investor. A successful investment in the safe project paid $\max \{0,7-w\}$ tokens to the manager and $\min \{7, w\}$ tokens to the investor (the manager is not liable for any loses imposed on the investor).

After each round, both managers observe the $w$ chosen by the other and which manager received the chip. In case the manager received the chip, she was also informed as to which project the chip was invested in, the resulting cash flow, and whether or not she was able to pay the investor in this round. The investor was told whether or not he received his payment and his profit in this round, but not which project the chip was invested in. The experiment then moved into the next round where subjects were randomly matched into new groups of 3 while retaining their role in the experiment, so that if a subject was an investor (manager) in round 1 she retained that role over the entire 20 rounds. The

\footnotetext{
${ }^{16}$ See Appendix for the instructions.
} 
identity of subjects was anonymous so subjects could not identify other subjects' roles. This eliminated the possibility of managers creating a reputation.

In addition to the Baseline treatment, we ran several other treatments each of which replicated one of the different contractual environments described above. The first such treatment is the Restricted treatment, for which we pick $\bar{x}=3$. This treatment was run to check our hypothesis that it is competition, and the heightened promises of returns it encourages, that lead to risky behavior on the part of investors. Obviously, since $3<3.25=w^{*}$, in this treatment we would expect all funds to be invested in the safe project. Otherwise, our hypothesis that risk taking is an artifact of market competition pushing promised returns above $w^{*}=3.25$ would be easily disproved. In this treatment all procedures were identical to those of the hedge fund contract except for the restriction on $w$.

Our Transparency treatment is identical to the baseline hedge fund contract except for the fact that in the first move of the game the managers not only choose $w$, but also commit on a project to invest in. In other words, they choose a pair ( $w$, Project) where Project $\in\{$ safe, risky\} and each pair chosen by the managers is shown to the investor. The investor then chooses a manager to give his chip to and the rest of the round is played out as in the Hedge Fund treatment.

Our fourth treatment is the Risk Sharing treatment. In this treatment $w=0$ and managers offer a share $1-\beta$ to the investor indicating what fraction of the returns investors will receive if the project succeeds. If $\beta=0$ then all the proceeds of the investments go to the investor, while if $\beta=1$ then the manager keeps all the proceeds for himself. This treatment is conducted using private information (when making their choice investors observe only the shares both managers propose) in an effort to isolate the impact of the contract on behavioral and not confound it with transparency considerations.

In all four treatments discussed above when the experiment was over we surprised the subjects by informing them that we wanted them to engage in one more decision. In this decision we gave each of them a chip and asked them to invest it for themselves in either the risky or the safe project. The chip was worth 10 times the value of the chip used in the previous 20 rounds so this decision was a more valuable one and should indicate how subjects would invest when investing their own money rather than that of others. This investment opportunity was given to both subjects who played the role of investors and managers in the experiment. We will refer to this part of the experiment as Own Money 
(big stakes) treatment.

The Own Money (big stakes) treatment is similar to the "surprise quiz" round used by Merlo and Schotter (1999). In this treatment subjects play for large stakes and do so only once after their multi-round participation in the experiment. The idea is that this one large-stakes decision should be a sufficient statistics for all they have learned during their participation in the experiment. ${ }^{17}$

Finally, we ran an an additional Own Money treatment which we call the Own Money (small stakes) treatment. In this treatment, all subjects participating in the experiment performed the role of managers. In each round (20 rounds in total) the manager was endowed with his/her own chip and faced the same two investment projects: safe and risky. The task of the manager was to choose how to invest his/her own chip. After the investment decisions were made the chosen project was played out, payoffs determined and shown to the subjects. As before, a successful investment in the risky project paid 10 tokens and a successful investment in the safe project paid 7 tokens.

The Own Money (small stakes) treatment is designed to replicate as close as possible the main features of the Risk Sharing treatment with one modification: managers are investing their own money ("investment chip") as opposed to the other people's money (the chip received from the investor). Indeed, similar to the other treatments, in the Own Money (small stakes) treatment the game is repeated (20 decision rounds), the stakes are of the same magnitude and, finally, subjects have no prior experience with the game being played.

Given the projects available, at equilibrium, managers invest their own funds in the safe project. This is the case also, at equilibrium, for the Risk Sharing treatment, in which managers invest funds received from the investor, because the preferences of the manager and the investor are completely aligned. Any difference we might observe in manager's behavior when they invest their own money and investors' money, will be interpreted as a manifestation of the Other peoples' money effect described in the Introduction.

Our complete experimental design is summarized in Table 2.

\footnotetext{
${ }^{17}$ In this sense it is preferable to repeating the Own Money (small stakes) treatment 20 times since in that treatment repetition may lead to boredom and false diversification.
} 
Table 2: Experimental Design

\begin{tabular}{l|l|l|l|l}
\hline \hline Treatment & Competition & Information & N of sessions & N of subjects \\
\hline Baseline & unrestricted & only $w$ & 2 sessions & 33 subjects \\
Restricted Competition & $w \leq 3$ & only $w$ & 2 sessions & 30 subjects \\
Risk Sharing & unrestricted & only $1-\beta$ & 2 sessions & 45 subjects \\
Transparency & unrestricted & $(w$, Project) & 2 sessions & 39 subjects \\
Own Money (small stakes) & none & NA & 1 session & 23 subjects \\
Own Money (big stakes) & none & NA & 8 sessions & 147 subjects \\
\hline \hline
\end{tabular}

\section{Results}

We now ask whether the predictions of the model is borne out in the lab. Our emphasis however is not on the model's point predictions. Rather, as is true in many experiments, we are more interested in its qualitative comparative statics since it is those that have the major policy implications.

Depending on the contractual environment, competition for funds might lead the market to unravel, inducing investment in a risky project when a safe project dominates in terms of expected returns. This is the case at equilibrium in the Baseline (hedge fund) contractual environment. The first fundamental question of the paper, therefore is,

1. Do managers tend to invest funds in the risky project in the Baseline treatment? Is the watermark $w$ they offer pushed up by competition?

On the other hand, all the other contractual environments we study experimentally predict that, at the equilibrium, managers invest in the safe project offering $w$ 's that vary with the contract used. The competitive mechanism leading to this outcome is however different in the different contractual environments. The second fundamental question of the experiment, therefore is,

2. Does the market in the Restricted Competition, Transparency, and Risk Sharing treatments lead more to investment in the safe project? Does the watermark $w$ respond to different contractual envioronment qualitatively as predicted by equilibrium analysis?

The other fundamental question we address in the paper regards the existence of an Other people's money effect. 
3. Do managers in the Own Money treatments tend to invest their own funds more safely than they invested their investors' money in the Risk Sharing treatment? Is there an Other people's moneyeffect?

After establishing the effects of the competition on the risk taking behavior of managers, we turn to investors' behavior and ask

4. Do investors choose the manager to invest with rationally? Do they anticipate the relationship between the return they are offered and the managers' investment strategy?

\section{Statistical Analysis}

To compare how often managers invest funds in the safe project in various treatments we run the following logistic regression:

$$
y_{i j}=\alpha+\beta \cdot \text { treatment }+\epsilon_{i j}
$$

where $y_{i j}$ is a dichotomous variable taking on a value of 1 if a manager (indexed by $i$ ) invested funds in the safe project in period $j$ and 0 otherwise and treatment is a dummy variable for the treatment. In all our experiments we used random matching design, in which subjects were rematched to form new groups in each period. Therefore, we cluster observations at the session level to allow for correlated errors within the session. To perform period-by-period analysis we run the same regression for each period separately. When we report $p$-values in our discussion below, they represent the significance of the coefficient $\beta$ in the regression.

To compare watermarks offered by the managers who chose to invest funds in the risky and the safe projects in the Baseline and Transparency treatments we use random effects GLS regression

$$
y_{i j}=\alpha+\beta \cdot r i s k y+\epsilon_{i j}
$$

where $y_{i j}$ is a continuous variable taking values between 0 and 10 , risky is a dummy variable that takes value 1 if the manager chose the risky project and 0 otherwise and panel id variable is the unique identifier of subjects that were managers in the experiments. The $p$-values we report represent the significance of coefficient $\beta$ in the regression. 


\subsection{Does the market unravel in the Baseline treatment?}

In the Baseline (hedge fund) contract environment, at equilibrium, managers are expected to offer the highest return $w=10$ and invest in the risky project. The key element in this result is that competition for funds will force $w$ above 3.25 at which point investing in the risky project becomes rational for the manager. In contrast, in the Restricted treatment, where $w \leq 3$, no funds should be invested in the risky project. Hence, our theory implies that it is competition that is responsible for risky investment since it succeeds in pushing $w$ above the critical threshold. If funds were invested in the risky project equally in these two treatments, then the obvious conclusion would be that it is not competition that leads to risky behavior but, perhaps, some type of risk seeking that arises especially when managers are investing other peoples' money. The cleanest way to identify such market unraveling in the Baseline treatment is to compare the outcome in this treatment and in the Restricted treatment.

Table 3: Fraction of Risky Investments

\begin{tabular}{l|c|c}
\hline \hline & All Periods & Last 5 Periods \\
\hline All Managers that received the chip & & \\
Baseline & $65 \%$ & $65 \%$ \\
Restricted Competition & $30 \%$ & $32 \%$ \\
\hline All Managers & $55 \%$ & $59 \%$ \\
Baseline & $31 \%$ & $31 \%$ \\
Restricted Competition & \\
\hline \hline
\end{tabular}

As Table 3 indicates, in all 20 rounds of the experiment, in the Baseline treatment managers invested the funds they received in the risky project $65 \%$ of the time, while this percentage is only $30 \%$ in the Restricted Competition treatment (where we actually predict it should be $0 \%$ ). Statistical analysis confirms this result: the managers are significantly more likely to invest funds received from the investors in the risky project in the Baseline than in the Restricted Competition treatment $(p<0.001$ in all rounds and $p=0.054$ in the last 5 rounds of the game). ${ }^{18}$ Despite the lack of total conformity to the quantitative predictions of the theory, we still see that qualitatively that competition for funds does lead to significantly more risky behavior on the part of investors, as is predicted.

\footnotetext{
${ }^{18}$ The results of the test do not change if we take into account all the intended investments of manager and not just the periods in which they received the chip from the investor $(p<0.001$ for all rounds and $p=0.007$ for the last 5 rounds).
} 


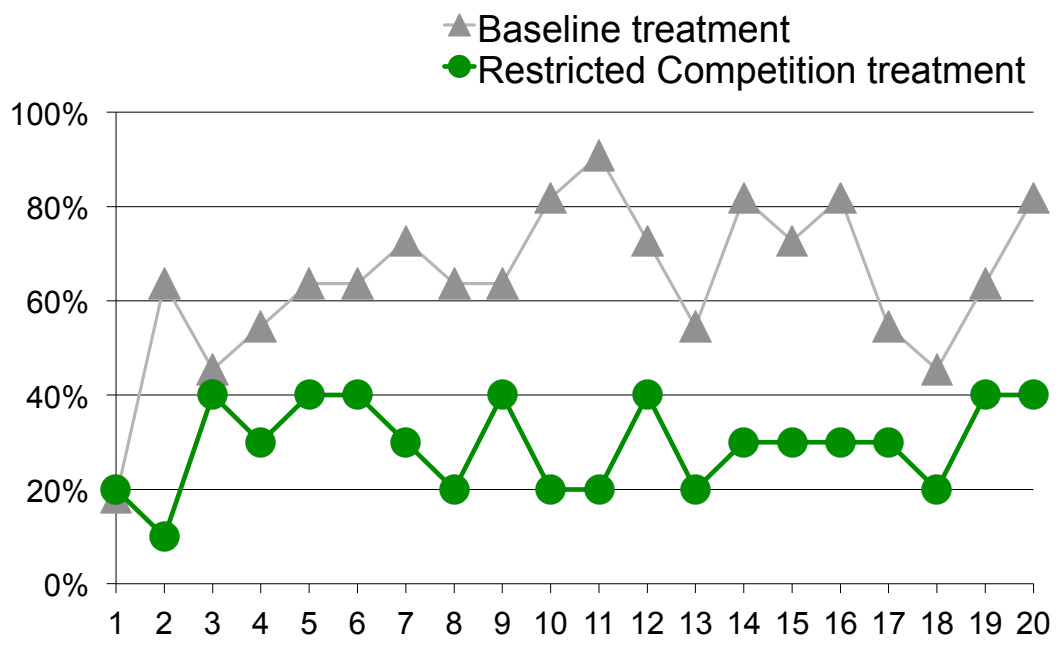

Figure 1: How often were chips received from investors invested in the risky project, dynamics

A period-by-period analysis of the investment decisions of the managers who received the fund to invest is even more striking. As we see in Figure 1, except for few early rounds, most managers in the Baseline treatment choose the risky project. Moreover, the fraction of risky investments in the Baseline treatment is bigger than that in the Restricted Competition treatment in every single round. In the regression analysis performed for each period separately, we obtain significantly different fractions in 13 out of 20 rounds of the experiment $(p<0.10){ }^{19}$

A second fundamental equilibrium prediction in the Baseline treatment is that risk taking on the part of managers is associated with high-return offers (high w's) to investors. In fact, in this environment the theory predicts that $w$ will rise to $R_{r}=10$. Qualitatively, all that matters in order to observe risky behavior is that the observed $w$ in the market rise above $w^{*}=3.25$ since such high promised returns are expected to lead to risky investments. This is once again the case in the lab data.

\footnotetext{
${ }^{19}$ Recall that in each period we only have 11 managers that received funds in the Baseline and 10 managers in the Restricted Competition treatment. Despite the small number of observations, in the majority of rounds the fraction of risky investments in the Baseline treatment is significantly bigger than that in the Restricted Competition treatment.
} 
Table 4: Offers of returns (w) in the Baseline treatment, in tokens

\begin{tabular}{l|c|c|c|c|c|c}
\hline \hline & \multicolumn{5}{|c}{ Periods } \\
\hline & all periods & 1 to 5 & 6 to 10 & 11 to 15 & 16 to 20 \\
\hline Managers that chose risky projects & 5.26 & 4.95 & 5.13 & 5.57 & 5.30 \\
Managers that chose safe projects & 4.60 & 4.23 & 4.63 & 4.81 & 4.86 \\
\hline \hline
\end{tabular}

Table 4 presents the offers of returns, $w$, for those managers intending to invest in the risky project and in the safe project.

Note that managers promised consistently, on average, more than 3.25. In the first 5 periods, we observe only $6.4 \%$ ( 7 out of 105 ) of offers $w<3.25$. In the remaining 15 periods this number drops to less than $3 \%$. Moreover, managers intending to invest in the risky project offer on average higher returns than those intending to invest in the safe project: managers that chose the risky project offer, on average, a return of 5.3 tokens and those that chose safe project offer, on average, lower returns of 4.6 tokens $(p<0.001$ in the regression analysis).

Notice that while our subjects in the Baseline treatment did not push the promised return up to their limit of 10 , as predicted, they did consistently push it above the threshold where risky behavior became rational. Of particular interest is the fact that for those managers intending to invest in the risky project, there seemed to be a great resistance to offering an $w$ much above 7 . Over all 20 rounds there are relatively few subjects who offered a $w$ higher than 7 . Even amongst those managers who attracted the chip we observe rarely a $w$ above 7 (6 out of 220 cases, less than $3 \%$ ). This may be true for a number of reasons. For example, in the Baseline treatment there is a residual $35 \%$ of subjects who invested in the safe project. For those subjects promising more than 7 was a losing proposition and rarely done. Hence, a manager intending to invest in the risky project may have believed that it was not necessary to offer more than 7 since there was a good chance that he would be facing a safe investor who he believed would never offer more than 7 .

In summary, on a qualitative level we find that, as predicted, competition in the Baseline treatment greatly increases the fraction of funds invested in the risky project and lead consistently to promised returns above $w^{*}=3.25$. 


\subsection{Do Transparency and Risk Sharing contracts lead to safe investments?}

From the equilibrium predictions of our theory we would expect that Transparency or Risk Sharing contracts would eliminate risky investment. This would be the case for different reasons, however. In the case of Risk Sharing, since $w=0$, the incentives of the manager and the investor are aligned. Since the safe project has a higher expected return, it is in the interest of the manager to invest in it so all funds should be invested in the safe project.

In the Transparency case it is competition that insures safe investment since the only equilibrium is one where both firms promise to invest safe and offer $w=7$ and, at that return, there exists no promised return that can induce the investor to want his chip invested in the risky project. As a result, we would expect less risky investment in the Risk Sharing and Transparency treatments than in the Baseline treatment.

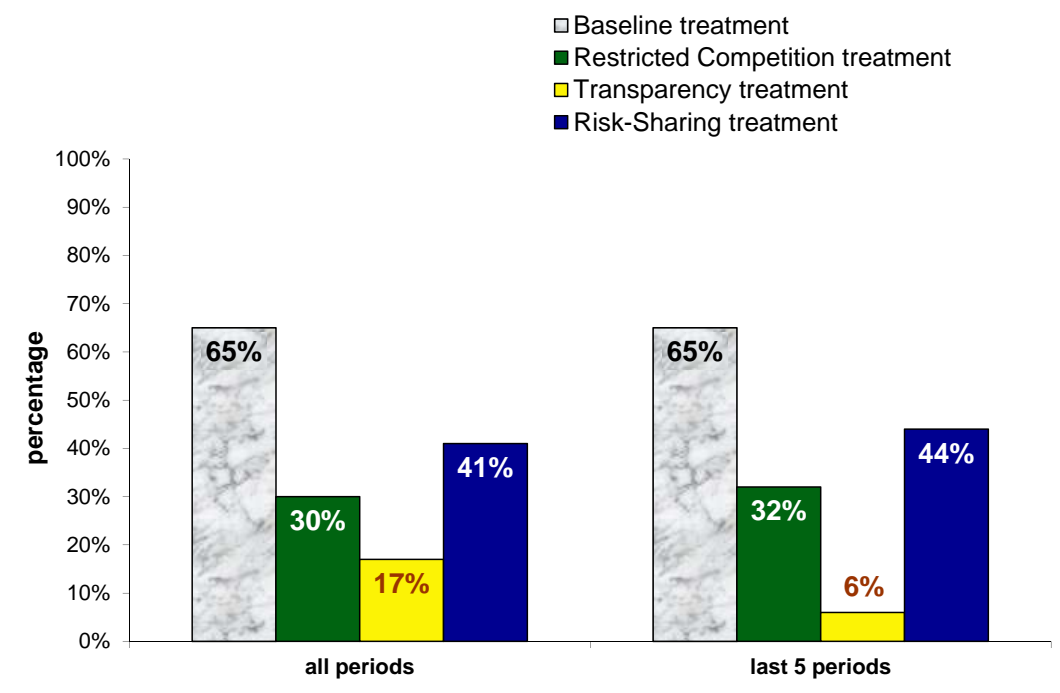

Figure 2: How often were chips received from investors invested in the risky project, by treatment

Figure 2 indicates that these expectations are substantiated by our data. As we can see, while subjects invested in the risky project $65 \%$ of the time over the 20 periods of the 
Baseline treatment ( $65 \%$ in the last 5 periods), the did so only $41 \%$ and $17 \%$ of the time in the Risk Sharing and Transparency treatments respectively (44\% and $6 \%$ in the last 5 periods respectively). Statistical analysis reveals that the fraction of risky investments in the Baseline treatment is signficantly higher than that in the Transparency treatment both in all 20 periods $(p=0.001)$ and in the last 5 periods $(p<0.001)$. In addition, we find that the fraction of risky investments is significantly higher in the Baseline than in the Risk Sharing treatment in all 20 periods of the experiment $(p=0.001)$, while it is not significantly different in the last 5 periods of the experiment $(p=0.118)$. Finally, we observe far less risky investments in the Transparency than in the Risk Sharing treatment: $p=0.092$ in all 20 periods of the experiment and $p=0.003$ for the last 5 periods.

The dramatic impact of transparency on the hedge fund contract is noteworthy since it indicates that investors in the experiment prefer to have their funds invested in the safe project and that the excessive risk taking in the Baseline treatment might be ascribed to investors inability to control how their funds are being invested. Moreover, the complete alignment of the preferences between the managers and investors (as imposed by Risk Sharing contract) might not be enough to reduce risk-taking behavior of the managers, which face competition for funds.

Our Result 2 implies that if one manager proposes to invest in the safe project while the other proposes to invest in the risky project, as long as the promised return on the risky project is more than $\frac{p_{s}}{p_{r}}$ times the promised return on the safe project (1.8 in our parameterization), the investor should prefer to invest his money in the risky project. Perhaps one of the reasons why we see so much investment in the safe project in the Transparency treatment is that while there is a significant premium for risky investment in this treatment (see Table 5), it is not sufficiently large to induce investors to want to go risky. For example, note that in the Transparency treatment the mean $w$ offered for investment in the safe project over all periods (last 5 periods) was 4.43 (4.90) while the same $w$ offered for investment in the risky project was 5.54 (5.86). While this premium is statistically significant $(p<0.001$ in all 20 rounds and $p=0.046$ in the last 5 rounds of the experiment), it is not, on average, as high as needed to be sufficient to make risky investment preferred by investors.

In the Risk Sharing treatment, managers that intended to invest in the risky and in the safe projects offered very similar shares of the proceeds to the investor: about $64 \%$ in all 20 rounds and about $74 \%$ in the last 5 rounds (see Table 5). Regression analysis shows that $\beta$ 's proposed by the managers who intended to invest in the risky and safe 
Table 5: Average offers of managers, by treatment

\begin{tabular}{l|c|c}
\hline \hline Transparency & $w$ in all rounds & $w$ in last 5 rounds \\
managers that chose risky project & 5.54 & 5.86 \\
managers that chose safe project & 4.43 & 4.90 \\
\hline Risk Sharing & $\beta$ in all rounds & $\beta$ in last 5 rounds \\
managers that chose risky project & $64.3 \%$ & $73.7 \%$ \\
managers that chose safe project & $63.7 \%$ & $74.1 \%$ \\
\hline \hline
\end{tabular}

projects were indistinguishable $(p>0.10)$. Thus, the investors could not infer from the promises made by managers whether their funds will be allocated to the safe or to the risky project.

\subsection{Is there an Other people's money effect?}

We say that an Other peoples' money effect occurs if managers tend to be more willing to take higher risks when investing other peoples' than their own money. To be precise, in our experimental set-up, we define the Other people's money effect as the difference in the risk taking behavior of managers in the Risk Sharing and Own Money treatments. In both treatments, in fact, managers' incentives are completely aligned with those of investors and theoretically, at equilibrium, we expect to see all funds invested in the safe project.

Table 6: How often funds were invested in the risky project (all managers)

\begin{tabular}{l|c|c|c}
\hline \hline & Risk Sharing & Own Money (small stakes) & Own Money (big stakes) \\
\hline rounds 1 to 5 & $36.7 \%$ & $23.5 \%$ & \\
rounds 6 to 10 & $42.0 \%$ & $21.7 \%$ & \\
rounds 11 to 15 & $46.7 \%$ & $19.1 \%$ & \\
rounds 16 to 19 & $40.8 \%$ & $16.3 \%$ & \\
round 20 & $43.3 \%$ & $43.5 \%$ & managers $10.2 \%$ \\
\hline all 20 rounds & $41.7 \%$ & $21.5 \%$ & investors $10.2 \%$ \\
& & & \\
\hline \hline
\end{tabular}

Table 6 presents the percentage of times subjects made risky investment in the Risk sharing and the Own money treatments. ${ }^{20}$ In the Own Money (big stakes) treatment only $10.2 \%$ of subjects (both managers and investors) invested their own funds in the risky

\footnotetext{
${ }^{20}$ We used the data from all the intended investments by managers in the Risk Sharing treatment, and not just the ones that actually got the chip.
} 
project, ${ }^{21}$ while they did so $41.7 \%$ of the time in the Risk Sharing treatment. In other words, if subjects have learned anything over the course of the 20 rounds experiment it is that they want their chip to be invested in the safe project when it is worth a lot of money.

Similar conclusions can be drawn from comparing the Risk Sharing and the Own Money (small stakes) treatments. Except for the very last round, subjects are much more likely to make risky investments when they allocate other people's money (41.7\%) than their own $(21.5 \%)$. Regression analysis confirms this result: the fraction of risky investments is significantly higher in the Risk Sharing than in the Own Money (small stakes) treatment in all 20 rounds of the experimet $(p<0.001)$ as well as in the last 5 rounds $(p=0.001)$. Moreover, if we perform the regression analysis period-by-period, we find that in 16 out of 20 periods of the expeirment, the fraction of risky investments in the Own Money (small stakes) treatment is significantly lower than in the Risk Sharing treatment $(p<0.05)$. Finally, results in Table 6 suggest that the fraction of risky investments monotonically decreases with experience in the Own Money (small stakes) treatment, while it is relatively constant in the Risk Sharing treatment. The last round of the Own Money (small stakes) treatment shows the end-game effect: in the last round $43.5 \%$ of the managers chose the risky project, which is two times more than the percentage of risky investments in the first 19 rounds where average is about $20 \% .{ }^{22}$

Figures 3 and 4 depicts the histograms and the cumulative distributions of the riskiness of the managers' investments in the Own Money (small stakes) and in the Risk Sharing treatments. To create Figures 3 and 4 we constructed one observation per manager, which indicates the fraction of the times he/she invested funds in the risky project over the course of 20 rounds of the experiment.

Figures 3 and 4 clearly show that managers were much more risky with the investors' money than with their own. Indeed, $52.2 \%$ of the managers in the Own Money (small stakes) treatment invested their own funds in the safe project $90 \%$ of the time or more. That is, more than half of managers chose the risky project at most twice out of 20 rounds played in the Own Money treatment. The same behavior is rare in the Risk

\footnotetext{
${ }^{21}$ Recall that the Own Money (big stakes) treatment was performed at the end of each session after another treatment. There is, however, no significant difference in the behavior of either managers or investors according to the the different treatments they previously played (Test of proportions, $p>0.10$ ). Therefore, we pool together all the data from Own Money (big stakes) treatment and report them together.

${ }^{22}$ End-game effects are often observed in the experiments on finitely repeated games. See, for instance, Reuben and Suetens (2009) and the references mentioned there for end-game effects in the repeated prisoners' dillemma game.
} 
Figure 3: Histogram of how often managers chose risky projects
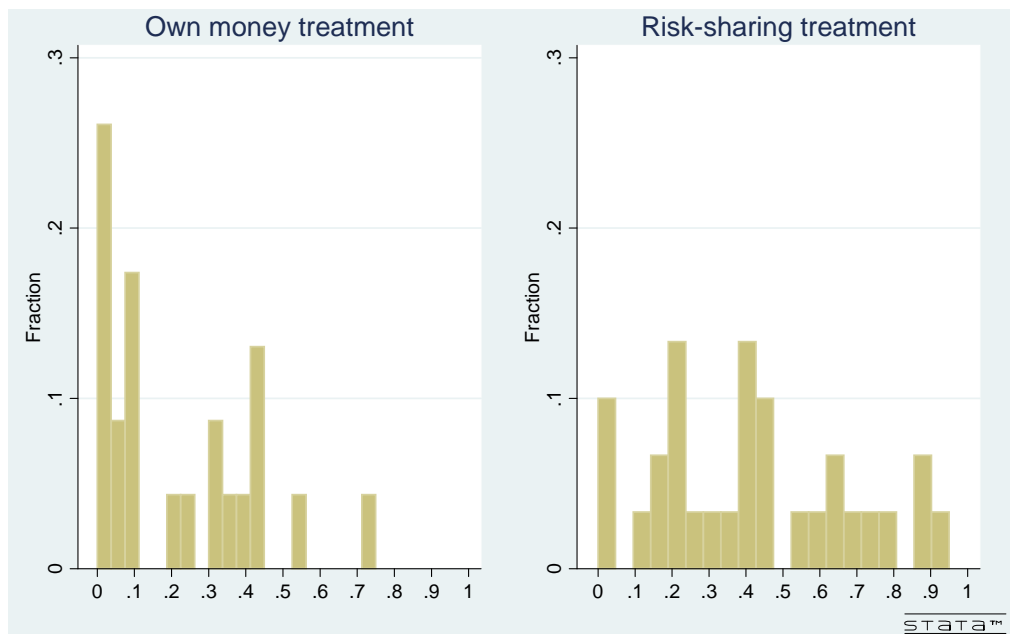

Figure 4: Cumulative distribution of how often managers chose risky projects

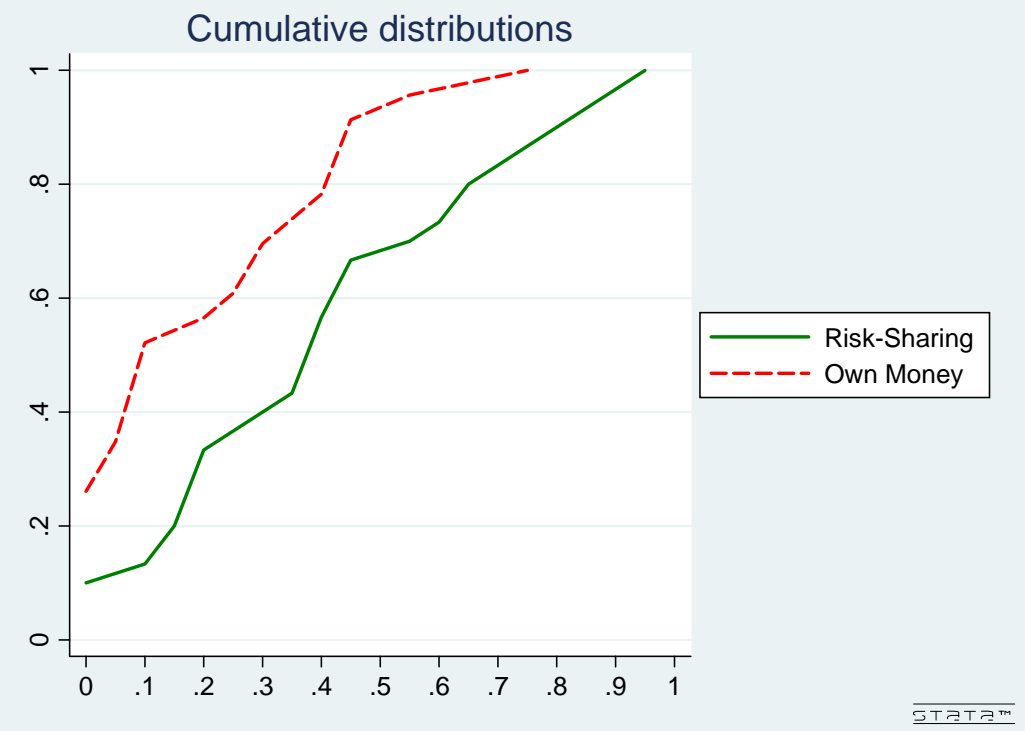


Sharing treatment, in which only $13.3 \%$ of the managers behave that way. According to Kolmogorov-Smirnov test, we reject the hypothesis that the distributions of the riskiness of the managers' investments are the same in these two treatments (corrected $p=0.022$ ).

This evidence for the Other people's money effect possibly suggests that framing the subjects' task as a competition for funds leads managers to want to take more risks, risks that they obviously would not want to take if they were investing their own money. It is natural to search for rationalizations of this effect in the realm of behavioral economics. For instance, managers might place other people's money in a different mental account than their own (see Thaler (1985), (1999)). In this case, the Other people's money effect we document is related to the House money effect discussed by Thaler-Johnson (1990) and Keasey-Moon (1996).

\subsection{How do investors behave?}

In this section we discuss the behavior of investors. Our objective here is to understand if the behavior of investors in our experimental data is also qualitatively consistent with equilibrium. This is particularly apparent in the Transparency treatment, where the rational action of investors is not confounded by their beliefs about which project the manager will invest in. In this treatment, over all 20 rounds there were 172 cases where both managers chose the same project. In 164 of these cases (95\%), investors, as expected, gave their chip to the manager offering the highest $w$. In 88 cases, one manager chose the risky project while the other chose the safe one. In 7 of these cases the risky manager promised 1.8 more than the safe one and in 5 of these $7(71.4 \%)$, the investors gave their chip to the risky manager. On the other hand, in 13 cases the safe manager promised more than the risky one and in all 13 cases (100\%) the investors gave the chip to the safe manager. Finally, in 68 cases the manager offering a risky investment promised more than the one offering a safe investment but less than 1.8 times more. Here the chip should go to the safe manager and it did so 58 out of 68 cases (85.3\%). All of these statistics are supportive of the hypothesis that investors behaved as we expected them to in the experiment. In all of these cases above (except for the 5 out of 7 cases), using a binomial test, we can reject the hypothesis that the chip was allocated randomly with a prob $=50 \%$. We observe very similar behavior of the investors in the last 5 rounds of the experiment, which we omit here for brevity. ${ }^{23}$

\footnotetext{
${ }^{23}$ Available from the authors upon request.
} 


\section{Conclusions}

In this paper we conducted a controlled experiment to investigate the impact of competition on the risk taking behavior of laboratory hedge fund managers who operate under the standard hedge fund option-like compensation contracts. We find that the competition for funds does indeed lead to an equilibrium where funds are invested in an inefficient risky manner. Interestingly, this happens in the environment in which the risky asset has both lower expected return and higher variance compared with the safe asset. ${ }^{24}$ This problem can be mitigated by either changing the contract type, restricting the watermark used in the hedge fund contract or by forcing managers to reveal the projects in which funds will be invested. We find that the transparency is the most efficient at eliminating the risky behavior of managers amongst the contracts we consider. Finally, we document that even when the incentives of the managers and the investors are completely aligned (as is the case in the risk-sharing contract), the managers tend to invest the money of others in a significantly more riskier manner than their own.

We stress that, while we couch our discussion with reference to the hedge fund market, our interests are broader than that since our results hold for any market where firms compete for funds.

There are several interesting characteristics of the environment in which hedge funds managers operate that we have abstracted from in this study. One of these elements is the dynamic nature of the interaction between managers and their reputation. Indeed, portfolio managers often compete with each other by providing potential investors with an information regarding their past performance. The reputation channel may by itself serve as a regulatory device that pushes managers to be more cautious with the risk taking. Future work should incorporate dynamic interactions between hedge fund managers and their reputational concerns into the theoretical and experimental framework. One of the interesting questions is whether reputation by itself can induce portfolio managers to efficiently invest funds in a safe asset as does imposing transparency.

\footnotetext{
${ }^{24}$ This suggests that the effects we found in the Baseline treatment would be even stronger in the situation, in which the risky asset has a higher expected return to compensate for the additional risk of holding this asset.
} 


\section{References}

[1] Agarval, Vikas, Naveen D. Daniel, and Narayan Y. Naik, 2008. "Role of managerial Incentives and Discretion in Hedge Fund Performance, forthcoming in Journal of Finance.

[2] Amin, Gaurav S. and Harry M. Kat, 2002. "Welcome to the Dark Side: Hedge Fund Attrition and Survivorship Bias Over the Period 1994-2001," ISMA Centre Discussion Papers In Finance 2002-02.

[3] Asparouhova, Elena, Peter Bossaerts, Jernej Copic, and Brad Cornell, 2011, "Competition in Portfolio Management: Theory and Experiment," mimeo, Caltech.

[4] Brennan, Geoffrey, Luis Gonzales, Werner Guth, and M. Vittoria Levati, 2008. "Attitudes toward Private and Collective Risk in Individual and Strategic Choice Situations," Journal of Economic Behavior and Organization, 67, 253-62.

[5] Brown, Stephen J. and William N. Goetzmann, 2001. "Hedge Funds with Style," Yale International Center for Finance, Working Paper No. 0029.

[6] Brown, Stephen J., William N. Goetzmann, and James Park, 2001."Careers and Survival: Competition and Risk in the Hedge Fund and CTA Industry," Journal of Finance, 56(5), 1869-86.

[7] Carpenter, Jennifer, 2000. "Does Option Compensation Increase managerial Risk Appetite?," Journal of Finance, 55(5), 2311-31.

[8] Chakravarty, Sunjoy, Glenn W. Harrison, Ernan E. Haruvy, and E. Elisabet Rutstrom, 2011. "Are You Risk Averse Over Other People's Money,?" Southern Economic Journal, 2011, 77(4), 901-913.

[9] Edwards, Franklin R. and Mustafa O. Caglayan, 2001. "Hedge Fund Performance and manager Skill," mimeo, Graduate School of Business, Columbia University.

[10] Ellison, Glenn and Judith Chevalier, 1999. "Carrer Concerns of Mutual Fund Managers," Quarterly Journal of Economics, 114(2), 389-432.

[11] Eriksen, Kristoffer W. and Ola Kvaloy, 2010. "Myopic Investment Management," Review of Finance, 14, 521-542.

[12] Foster, Dean P. and H. Peyton Young, 2008. "The Hedge Fund Game: Incentives, Excess Returns, and Piggy-Backing," Economic Series Working Papers 378, University of Oxford. 
[13] Fung, William and David A. Hsieh, 1999. "A Primer on Hedge Funds," Journal of Empirical Finance, 6, 309-31.

[14] Goetzmann, William N., Jonathan Ingersoll Jr., and Stephen A. Ross, 2003. "High Water Marks and Hedge Fund Management Contracts," Journal of Finance, 58(4), 1685-718.

[15] Richard C. Green and Jonathan Berk, 2002. "Mutual fund flows and performance in rational markets," NBER Working Paper 9275.

[16] He, Zhiguo and Wei Xiong, 2010. "Delegated Asset Management and Investment Mandates," mimeo, University of Chicago Booth School of Business.

[17] Inechen, Alexander and Kurt Silberstein, 2008. "Aima's Roadmap to Hedge Funds," The Alternative Investment Management Association Limited.

[18] Jackwerth, Jens C. and James E. Hodder, 2006. "Incentive Contracts and Hedge Fund Management," MPRA Paper No 11632.

[19] Levitt, Steven D. and Chad Syverson, 2008. "Market Distortions When Agents Are Better Informed: The Value of Information in Real Estate Transactions," The Review of Economics and Statistics, MIT Press, vol. 90(4), 599-611.

[20] Liang, Bing, 200. "Hedge Funds: The Living and the Dead," Journal of Finance and Quantitative Analysis, 35(3), 309-26.

[21] Malkiel, Burton G. and Atanu Saha, 2005. "Hedge Funds: Risk and Return," Financial Analysist Journal, 61(6), 80-8.

[22] Matutes, Carmen and Xavier Vives, 2000. "Imperfect Competition, Risk Taking, and Regulation in Banking," European Economic Review, 44, 1-34.

[23] Merlo, Antonio and Schotter, Andrew, 1999. "A Surprise-Quiz View of Learning in Economic Experiments," Games and Economic Behavior, 28(1), 25-54.

[24] Ou-Yang, Hui, 2003. "Optimal Contracts in a ContinuousâTime Delegated Portfolio Management Problem" Review of Financial Studies, 16(1), 173-208.

[25] Frederic Palomino and Andrea Prat, 2003. "Risk taking and optimal contracts for money managers," RAND Journal of Economics, 34(1),113-137.

[26] Panageas, Stavros and Mark M. Westerfield, 2009. "High-Water Marks: High Risk Appetites? Convex Compensation, Long Horizons, and Portfolio Choice," Journal of Finance, 64(1), 1-36. 
[27] Reuben, Ernesto and Sigrid Suetens, 2009. "Revisiting Strategic versus NonStrategic Cooperation," CentER discussion paper 2009-22.

[28] Thaler, Richard H., 1985. "Mental Accounting and Consumer Choice," Marketing Science, 4(3), 199-214.

[29] Thaler, Richard H., 1999. "Mental Accounting Matters," Journal of Behavioral Decision Making, 12, 183-206.

[30] Thaler, Richard H. and Eric J. Johnson, 1990. "Gambling with the House Money and Trying to Break Even: The Effects of Prior Outcomes on Risky Choices," Management Science, 36(6), 643-660. 


\section{Appendix 1: A Note on Hedge Fund Contracts}

As we described in Section 2, a typical hedge fund contract specifies a pair $(w, \beta)$ which represents a watermark $w$ and a share $\beta$ of profits above watermark that managers keeps for himself. We will show below that,

if $\beta \geq \bar{\beta}>0^{25}$ there exists an equilibrium in which all the funds are invested in the risky project.

We will show that we can sustain an equilibrium in which both managers propose contract with $w=R_{r}, \beta \in[\bar{\beta}, 1]$ and invest in the risky project.

First, similarly to the Result 1, if $w>w^{*}$ then a manager will prefer to invest in the risky project because

$$
\begin{aligned}
\Pi_{w, \beta, \text { safe }}^{\text {manage }} & <\Pi_{w, \beta, \text { risky }}^{\text {manager }} \Leftrightarrow p_{s} \beta\left(R_{s}-w\right)<p_{r} \beta\left(R_{r}-w\right) \\
& \Leftrightarrow w>w^{*}=\frac{p_{s} R_{s}-p_{r} R_{r}}{p_{s}-p_{r}}
\end{aligned}
$$

Thus, when an investor gives his funds to a manager that promised $w=R_{r}$, his funds will be invested in the risky project.

To sustain the equilibrium proposed above, the only deviation that we need to rule out is the one in which one of the managers proposes $w=w^{*}$ and $\beta^{\prime} \in[\bar{\beta}, 1]$. If this proposal attracts the investor, then it is clearly beneficial for the manager because it gives him/her positive expected profits, as opposed to the zero profits which is what he/she earns following strategy $w=R_{r}$ and $\beta \in[\bar{\beta}, 1]$. However, this deviation will attract the investor only if $\prod_{w=R_{r}, \beta}^{\text {investor }}<\prod_{w=w^{*}, \beta^{\prime}}^{\text {investo }}$. Thus, to rule out this deviation we need to make sure that $\prod_{w=R_{r}, \beta}^{\text {investor }} \geq \prod_{w=w^{*}, \beta^{\prime}}^{\text {investor }}$. But:

$$
p_{r} \cdot R_{r} \geq p_{s} \cdot\left[w^{*}+\left(1-\beta^{\prime}\right)\left(R_{s}-w^{*}\right)\right] \Leftrightarrow \beta^{\prime} \geq \beta^{*}=\frac{p_{s} R_{s}-p_{r} R_{r}}{p_{s}\left(R_{s}-w^{*}\right)}
$$

Thus if $\beta^{*}<\bar{\beta}$ then for any $\beta^{\prime} \in[\bar{\beta}, 1]$, there exists an equilibrium in which all the funds received from an investor are allocated to the risky project.

We interpret therefore the assumption that $\beta=1$, which we adopted in the paper, as a simplification of the analysis.

\footnotetext{
${ }^{25}$ In fact, in the hedge fund markets, managers typically keep $15-25 \%$ of returns exceeding the watermarks. Thus, we will focus on the situation in which this share $\beta$ is bounded away from zero.
} 


\section{Appendix 2: Instructions for the Baseline Treat- ment}

This is an experiment in decision-making. If you follow the instructions and make good decisions, you can earn a substantial amount of money, which will be paid to you at the end of the session. The currency in this experiment is called tokens. All payoffs are denominated in this currency. The experiment consists of $\mathbf{2 0}$ identical decision rounds. At the end of the experiment, we will sum up the tokens you earned in all 20 rounds and this amount will be converted into US dollars using a conversion rate of 10 tokens $=\$ 1$. In addition, you will receive a participation fee.

Before the beginning of the experiment you will be randomly assigned roles: $\frac{2}{3}$ of the participants will be assigned a role of investors and $\frac{1}{3}$ of participants will be assigned a role of lenders. The role of an investor will be to invest an "investment chip" if one given to him by the lender, while the role of the lender will be to decide whom to given his investment chip to. Roles stay fixed until the end of the experiment. That is, if at the beginning of the experiment you were assigned the role of an investor (lender) you will keep this role for all 20 rounds.

In each round, participants will be randomly matched into the groups of 3 people. Each group consists of two investors and one lender. Once the round is over, you will be rematched with other participants for the next round. However, there will always be two investors and one lender in every group. The investors will receive a participation fee of $\$ 10$ and lenders will receive a participation fee of $\$ 5$.

\section{Decision of the investors in each period.}

Each period starts with the lender being given one chip which he/she will lend to one of the investors in their group. This chip has no value other than providing the right to get a return if it is invested, i.e. it cannot be converted to tokens. Investors are the ones who decide how a chip received from the lender is invested and how many tokens the lender will receive if the investment is successful.

There are two investment projects: Project 1 and Project 2, which differ in the returns and the probability of defaulting:

- Project 1 pays back 10 tokens with probability $50 \%$ and 0 tokens with probability $50 \%$. 
- Project 2 pays back 7 tokens with probability $90 \%$ and 0 tokens with probability $10 \%$.

In other words, Project 1 has a return of 10 tokens and 50\% probability of defaulting. Project 2 has return of 7 tokens and $10 \%$ probability of defaulting.

Each period starts with the investors making two decisions. First, each Investor chooses how many tokens he is willing to pay to the lender that lends him his/her chip in case the investment is successful. Second, each investor chooses a Project in which the chip received from the lender will be invested. The number of tokens that the investor can pay the lender for a chip can be any number between 0 and 10 tokens with one digit after decimal, i.e. numbers like $3.2,4.6,5.9,8.6$ etc... This number represents how many tokens an investor will pay the lender that lends him his/her chip in case the project in which this chip was invested was successful. If the project in which the chip was invested defaulted, then both the investor and the lender get zero tokens. Each investor makes his/her choice without knowing what the other investor from his group chose.

\title{
Decision of lenders in each period.
}

After both investors make their choices, the lender observes how many tokens each investor promises to pay to the lender that gives him his chip. The lender's task is to choose which investor he/she is willing to lend his chip to. Notice that lenders do not observe which project the investor chose to invest in (project 1 or 2); they observe only the promises of the investors in their own group. The screen for the lenders will look like this

\author{
Investor A promised to pay back $x$ tokens \\ Investor B promised to pay back $y$ tokens
}

It is important to note that in each round, the lender is matched with different investors. Therefore, it is impossible to track the same investor between periods. For instance, an investor who appears as Investor A in one round is not the same person as investor who appears as Investor A in the next round.

\section{How the profits of the investors and the lender are determined.}

In any period, an investor that did not receive a chip from the lender will receive zero tokens in that period. 
If the investor who did receive a chip and promised to pay back $x$ tokens, then

- if the project in which the chip was invested defaulted, both the investor and the lender get 0 tokens in that period

- if the chip was invested in Project 1 and did not default, then the investor gets $10-x$ tokens in that period and the lender gets $x$ tokens as promised.

- if the chip was invested in Project 2, did not default and $x \leq 7$, then the investor gets $7-x$ tokens in that period and the lender gets $x$ tokens as promised.

- if the chip was invested in Project 2, did not default and $x>7$, then the investor gets 0 tokens in that period and the lender gets 7 , which is less than what investor promised to him.

\section{Quiz.}

\section{Question 1}

Say an investor that received a chip from the lender promised to pay back 7.3 tokens, invested this chip in Project 1 and Project 1 did not default. What is the profit of the lender in this period? What is the profit of the investor that received the chip in this period? What is the profit of the other investor from the same group? What is the profit is each subject in a group if Project 1 defaulted?

\section{Question 2}

Say investor that received the chip from the lender promised to pay him back 4.9 tokens, invested this chip in Project 2, which did not default. What is the profit of the lender in this period? What is the profit of the investor that received the chip? What is the profit of the other investor from the same group?

\section{Investor's feedback.}

At the end of each period investors observe the following information: how many tokens he/she promised to pay back to a lender that lends him/her chip; how many tokens the other investor promised to pay back to lender; whether or not the investor received the chip from the lender; in case the investor received the chip from the lender, which 
project was the chip invested in and whether the project was successful or not; whether the investor was able to repay the lender what he promised and profits of the investor in tokens. You will not be told what project the other investor decided to invest in.

\section{Lender's feedback.}

At the end of each period the lender observes the following information: how many tokens each investor promised to repay to a lender that gives him his chip; which investor he/she chose to lend the chip to and whether this investor was able to repay the promised return or not. The lenders are also informed about how many tokens they received in this period.

\section{To summarize:}

- At the beginning of the experiment, subjects are assigned roles of investors and lenders, which they keep for the whole duration of the experiment.

- In each period subjects are divided into the groups of 3 people: two investors and one lender.

- Each period starts with the decision of investors as to how many tokens they promise to repay to a lender that gives him/her an investment chip and which project, 1 or 2 , the chip received from the lender will be invested in.

- The lenders observe the promised returns and choose one investor in their group to lend chip to

- The chip received by an investor is then invested in the project of his/her choice as determined at the beginning of the period

- Payoffs are realized and all lenders and investors observe how many tokens they receive in this period

- At the end of the experiment all tokens earned in these 20 periods will be summed up and their sum converted to US dollars at a rate of 10 tokens $=\$ 1$. In addition, you will receive a participation fee.

\section{Last part of the experiment.}

In this part of the experiment we will ask you all to act as an investor for one period and make one investment decision with an investment chip which we will give you. Please choose whether you want to invest in Project 1 or Project 2: 
- Project 1 pays back 10 tokens with probability 50\% and 0 tokens with probability $50 \%$

- Project 2 pays back 7 tokens with probability $90 \%$ and 0 tokens with probability $10 \%$

After you made your decision, we will roll a 10-sided dice to determine whether the project you invested in defaulted or paid back. If you invested in Project 1 and dice lands on $0,1,2,3$ or 4 then Project 1 defaults and you get 0 tokens. If it lands on any number strictly above 4 (that is, 5, 6, 7, 8 or 9 ) then you get 10 tokens. If you invested in Project 2 and dice lands on 0 then Project 2 defaults and you get 0 tokens. If it lands on any other number $(1,2,3,4,5,6,7,8$ or 9$)$ then you will get 7 tokens.

Amount of tokens you earn in this part will be converted into US dollars, using the conversion rate 1 token $=\$ 1$, and added to your total payment.

Please circle the Project in which you want to invest your investment chip: 